\title{
Electromagnetic Fields at the Top of a Tall Building Associated With Nearby Lightning Return Strokes
}

\author{
Yoshihiro Baba, Member, IEEE, and Vladimir A. Rakov, Fellow, IEEE
}

\begin{abstract}
We have calculated, using the finite-difference timedomain (FDTD) method for solving Maxwell's equations, the vertical electric field $E_{z}$ and azimuthal magnetic field $H_{\varphi}$ due to lightning return strokes in the presence and in the absence of a building at the field point. Strikes to both flat ground and tall objects of height $h=100,200$, or $500 \mathrm{~m}$ are considered. The magnitude of $H_{\varphi}$ is not much influenced by the presence of either building at the field point or strike object, while the magnitude of $E_{z}$ is significantly influenced by either of them. In the case of a lightning strike to flat ground, the magnitude of $E_{z}$ at the top of the building (at the center point of its flat roof) of plan area $S_{b}=$ $40 \times 40 \mathrm{~m}^{2}$ and height $h_{b}=20,50$, or $100 \mathrm{~m}$ located at horizontal distance $d$ ranging from 100 to $500 \mathrm{~m}$ from the lightning channel is about $1.5,2$, or 3 times, respectively, greater than that at the same horizontal distance on the ground surface in the absence of the building. The enhancement factor for lightning (transient) $E_{z}$ due to the presence of the building at the field point is essentially not influenced by the presence of the strike object (up to $500 \mathrm{~m}$ in height) and is similar to the static electric field enhancement factor due to the presence of the same building in a uniform vertical electric field. The magnitude of the electric field at the corner of the building is about two to three times larger than that at the center point of its flat roof. The magnitude of $E_{z}$ at the ground level in the immediate vicinity of the building is reduced relative to the case of no building, with this shielding effect becoming negligible at horizontal distances from the building exceeding twice the height of the building.
\end{abstract}

Index Terms-Building, electric field, finite-difference timedomain (FDTD) method, lightning, lightning electromagnetic environment, lightning return-stroke model, magnetic field, tall object.

\section{INTRODUCTION}

I $\mathrm{N}$ URBAN areas, there are many tall buildings with heights of several tens of meters to greater than $100 \mathrm{~m}$. In order to optimize lightning protection means of tall buildings in such an area, it is important to know "transient" electric field enhancement at the top of the building due to lightning strikes to other buildings nearby. Further, lightning electric field measurements in urban areas are often made on the roof of tall buildings (e.g., [1]-[5]), so that the field enhancement factor due to the presence of a building is needed for proper interpretation of

Manuscript received July 15, 2006; revised April 12, 2007. This work was supported in part by the Japan Society for the Promotion of Science under Grant 18760220 and in part by the National Science Foundation under Grant ATM0346164.

Y. Baba is with the Department of Electrical Engineering, Doshisha University, Kyoto 610-0321, Japan (e-mail: ybaba@mail.doshisha.ac.jp).

V. A. Rakov is with the Department of Electrical and Computer Engineering, University of Florida, Gainesville, FL 32611 USA (e-mail: rakov@ece.ufl.edu). Digital Object Identifier 10.1109/TEMC.2007.902402 measurements. Also, electric field measurements on the ground surface near tall buildings may be influenced by the presence of a building (shielding effect). Additionally, the field enhancement factor near the top of the building is of interest in evaluating the potential for upward discharges in response to nearby lightning strikes.

Rubinstein et al. [2] have estimated the value of electric-field enhancement factor due to the presence of a 17-storied building, on which electric fields are measured, to be about 1.5 (according to Bermudez et al. [5]) on the basis of their simultaneous measurements of lightning electric fields on the roof of the building and at ground level. Bonyadi-ram et al. [6] have calculated, using the method of moments in the time domain [7], the values of the electric-field enhancement factor due to the presence of buildings of different heights at the field point (location where fields are measured or calculated). The calculated values are $3.5,5.3$, and 6.2 for buildings of heights 20,40 , and $60 \mathrm{~m}$, respectively. In their calculations, the building, represented as a metal-grid parallelepiped located on a flat perfectly conducting plane, was illuminated by a Gaussian-pulse-shape transverse electromagnetic (TEM) wave having a half-peak width of about $0.3 \mu \mathrm{s}$, which differs considerably from lightning return-stroke field waveforms. Bermudez et al. [5] have compared peak values of vertical electric and azimuthal magnetic fields, which are associated with lightning strikes to the 553-m-high CN Tower (Toronto, Canada) and measured on the roofs of four-storied buildings at distances 2 and $17 \mathrm{~km}$ from the $\mathrm{CN}$ Tower, with those calculated using their analytical (model-based) expressions. Peak values of both vertical electric and azimuthal magnetic fields measured on the roofs of the buildings were found to be 1.4 times larger than those calculated using their analytical expressions. Bermudez et al. [5] have given the following possible reasons for this discrepancy: the uncertainity in the adopted values for current reflection coefficient at the tower top and for return-stroke wavefront speed; assumptions in the theoretical model and experimental errors; the fact that at $2 \mathrm{~km}$ from the $\mathrm{CN}$ Tower, not only the radiation component but also the induction and electrostatic components (the latter two disregarded in their model) of the electric field contribute to the field peak value; the effect of reflections at the structural discontinuities of the $\mathrm{CN}$ Tower; and the field enhancement effect of the building on which the electromagnetic field sensors were installed. Note that Bermudez et al.'s [5] analytical field expressions include the effect of the presence of the strike object, the CN Tower (its electric-field enhancement factor estimated by Bermudez et al. is 3.9), but do not consider the presence of the building at the field point. Enhancement of lightning fields due to the presence of a tall strike object was also studied 
by Diendorfer and Schulz [8], Rachidi et al. [9], Pavanello et al. [10], Miyazaki and Ishii [11], and Baba and Rakov [12]. Static-field enhancement factors for structures of different geometry were studied by Johns and Kreielsheimer [13], Anderson [14], Bazelyan et al. [15], and Crawford [16].

It follows from the previous description that the electric field can be significantly enhanced due to the presence of a building at the field point. It is also known that the ground-surface electric field can be reduced due to the presence of a building nearby. Several aspects of the lightning electromagnetic environment in the presence of a tall building, however, have not yet been fully (if at all) examined, including the magnetic field at the top of the building; fields at the top of the building at the field point in the case of lightning strikes to tall objects; and effects of the conductivities of ground and building, and of the return-stroke current waveshape.

In this paper, we will calculate, using the 3-D finite-difference time-domain (FDTD) method [17] for solving Maxwell's equations, the transient vertical electric fields on the roof of a building due to nearby lightning strikes to a tall grounded object and to flat lossy ground and compare these fields with their counterparts in the absence of the building. We will also examine the transient azimuthal magnetic field both in the presence and in the absence of the building. In doing so, we will represent both the lightning channel and the strike object by the "engineering" transmission-line (TL) model described by Baba and Rakov [18], and the grounded building by a conducting parallelepiped.

The paper is organized as follows. In Section II, we present the methodology for examining transient electric and magnetic fields due to lightning strikes to a tall grounded object of height $h=100,200$, or $500 \mathrm{~m}$ and to flat ground in the presence and in the absence of a building of height $h_{b}=20,50$, and $100 \mathrm{~m}$ at the field point. In Section III, we compare vertical electric and azimuthal magnetic fields in the presence of the building with their counterparts in the absence of the building, both calculated using the FDTD method. Further, we investigate the influences on the vertical electric and azimuthal magnetic fields of the conductivity of the ground $\left(\sigma_{g}=1 \mathrm{mS} / \mathrm{m}\right.$ and infinity) and the building ( $\sigma_{b}=0.01 \mathrm{mS} / \mathrm{m}, 1 \mathrm{mS} / \mathrm{m}$, and infinity), the plan area of the building $\left(S_{b}=20 \times 20\right.$ and $\left.40 \times 40 \mathrm{~m}^{2}\right)$, and the return-stroke current 10 -to-90\% risetime $(\mathrm{RT}=0.15$ and $1.4 \mu \mathrm{s})$. In Appendix A, in order to test the validity of our FDTD calculations, we compare the magnitudes of the vertical electric and azimuthal magnetic fields (in the absence of the building) due to a lightning strike to flat perfectly conducting ground calculated using the FDTD method with those calculated using exact analytical expressions derived by Thottappillil et al. [19] for this configuration and the TL model with return-stroke speed equal to the speed of light. In Appendix B, we compare the value of the FDTD-calculated static electric-field enhancement factor due to the presence of a perfectly conducting discretized hemisphere placed on a flat perfectly conducting plane in a uniform vertical electric field with the theoretical value equal to 3. We also present in Appendix B, the FDTD-calculated values of static electric-field enhancement factor for buildings of height $h_{b}=20,50$, and $100 \mathrm{~m}$.

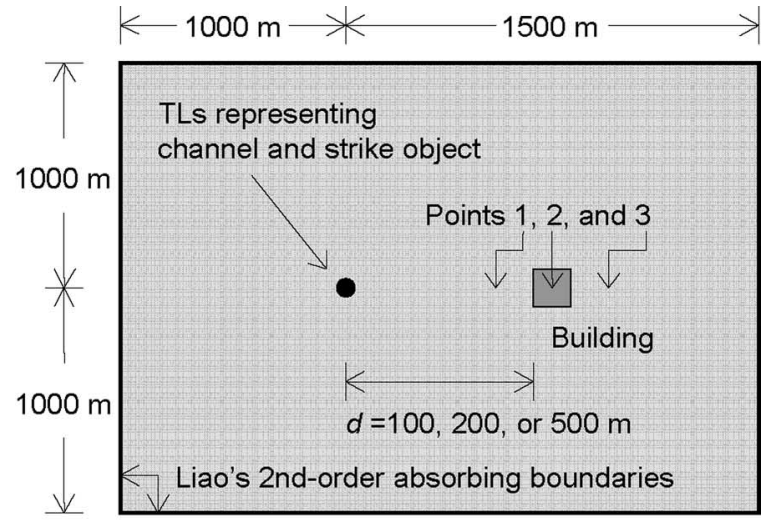

Plan view

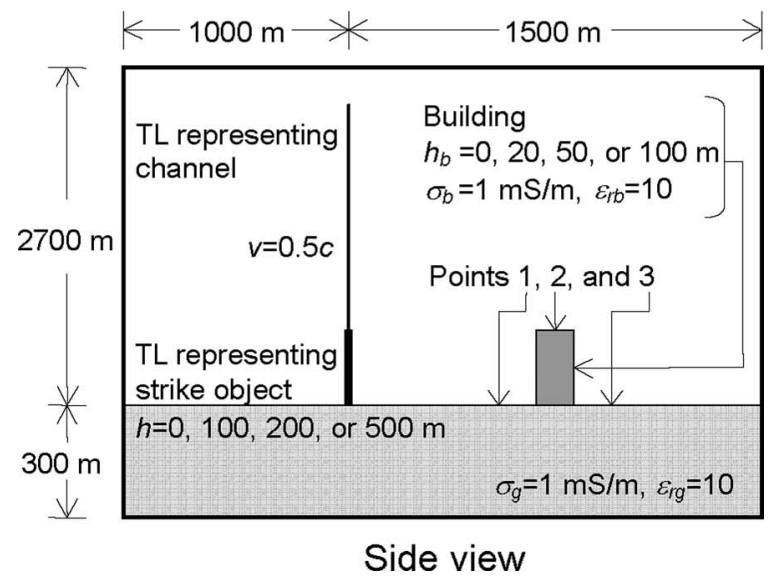

Fig. 1. Building of height $h_{b}=0$ (for the case of no building), 20, 50, or $100 \mathrm{~m}$ and plan area $S_{b}=40 \times 40 \mathrm{~m}^{2}$ located at distance $d=100,200$, or $500 \mathrm{~m}$ from a tall grounded object of height $h=0$ (for the case of lightning strike to flat ground), 100, 200, or $500 \mathrm{~m}$ struck by lightning. The strike object and the lightning channel are represented by a vertical array of current sources specified using the "engineering" TL model described by Baba and Rakov [18]. The current propagation speed along the lightning channel is set to $v=0.5 c$ The working volume of $2000 \times 2500 \times 3000 \mathrm{~m}^{3}$ is divided into $10 \times 10 \times$ $10 \mathrm{~m}^{3}$ cubic cells and surrounded by six planes of Liao's second-order absorbing boundary condition [21] to avoid reflections there.

\section{Methodology}

The configuration examined in this study is presented in Fig. 1, which shows a building of height $h_{b}=0$ (for the case of no building), 20, 50, or $100 \mathrm{~m}$ and plan area $S_{b}=40 \times 40 \mathrm{~m}^{2}$ located at a distance $d=100,200$, or $500 \mathrm{~m}$ from a grounded strike object of height $h=0$ (for the case of lightning strike to flat ground), 100,200 , or $500 \mathrm{~m}$. The length of the vertical lightning channel is set to $2000 \mathrm{~m}$. The conductivity, relative permittivity, and relative permeability of the ground are set to $\sigma_{g}=$ $1 \mathrm{mS} / \mathrm{m}$ or infinity, $\varepsilon_{\mathrm{rg}}=10$, and $\mu_{\mathrm{rg}}=1$, respectively. Those of the building are set to $\sigma_{b}=1 \mathrm{mS} / \mathrm{m}, \varepsilon_{\mathrm{rb}}=10$, and $\mu_{\mathrm{rb}}=1$, respectively. These values are intended to simulate a building made of concrete in a dry condition [20]. Further, we will consider the case of a perfectly conducting building by setting $\sigma_{b}$ to infinity in order to examine the influence of steel rebar used for reinforcement in concrete structures. We will additionally consider $\sigma_{b}=0.01 \mathrm{mS} / \mathrm{m}$ in order to see how sensitive the 
result is to such a large decrease in $\sigma_{b}$. Electric and magnetic fields are calculated using the FDTD method for solving the discretized Maxwell's equations with a time increment of $10 \mathrm{~ns}$. The working volume of $2000 \times 2500 \times 3000 \mathrm{~m}^{3}$ (see Fig. 1) is divided into $10 \times 10 \times 10 \mathrm{~m}^{3}$ cubic cells and surrounded by six planes of Liao's second-order absorbing boundary condition [21] to avoid reflections there. Testing of the applicability of our FDTD approach to calculation of lightning electromagnetic fields is found in Appendix A and in Baba and Rakov [22], [23]. Note that the reason for the use of relatively large cells $(10 \times$ $\left.10 \times 10 \mathrm{~m}^{3}\right)$ is the limited memory capacity of the personal computer used in this work. Since FDTD-calculated waveforms of vertical electric field and azimuthal magnetic field as close as five cells $(50 \mathrm{~m})$ away from the vertical lightning channel [see Fig. 10(a) and (b) in Appendix A] agree well with the corresponding waveforms calculated using exact equations [19], we conclude that FDTD-calculation errors due to the use of $10 \times$ $10 \times 10 \mathrm{~m}^{3}$ cells are not significant.

In order to find the distribution of current along both the lightning channel and the strike object, we use the "engineering" TL model described by Baba and Rakov [18]. The reason why we use the engineering TL model instead of an electromagnetic return-stroke model (e.g., [24] and [25]), which would allow a self-consistent full-wave solution for both lightning-current distribution and fields, is that the TL model allows one to set more directly the speeds of current waves along the strike object and the channel, as well as reflection coefficients at the extremities of the strike object.

For the case of lightning strike to a tall object, equations for return-stroke current, $I\left(z^{\prime}, t\right)$, along the strike object $(0 \leq$ $\left.z^{\prime} \leq h\right)$ and along the lightning channel $\left(\mathrm{z}^{\prime} \geq h\right)$, are given by Baba and Rakov [18] and reproduced as follows:

$I\left(z^{\prime}, t\right)=\frac{1-\rho_{\text {top }}}{2} \sum_{n=0}^{\infty}\left[\begin{array}{c}\rho_{\text {bot }}^{n} \rho_{\text {top }}^{n} I_{\mathrm{sc}}\left(h, t-\frac{h-z^{\prime}}{c}-\frac{2 n h}{c}\right) \\ +\rho_{\text {bot }}^{n+1} \rho_{\text {top }}^{n} I_{\mathrm{sc}}\left(h, t-\frac{h+z^{\prime}}{c}-\frac{2 n h}{c}\right)\end{array}\right]$

for $0 \leq z^{\prime} \leq h$ (along the strike object)

$$
\begin{aligned}
& I\left(z^{\prime}, t\right)=\frac{1-\rho_{\text {top }}}{2} \\
& {\left[\begin{array}{l}
I_{\mathrm{sc}}\left(h, t-\frac{z^{\prime}-h}{v}\right) \\
+\sum_{n=1}^{\infty} \rho_{\text {bot }}^{n} \rho_{\text {top }}^{n-1}\left(1+\rho_{\text {top }}\right) I_{\mathrm{sc}}\left(h, t-\frac{z^{\prime}-h}{v}-\frac{2 n h}{c}\right)
\end{array}\right]}
\end{aligned}
$$

for $z^{\prime} \geq h$ (along) the lightning channel) where $I_{\mathrm{sc}}(h, t)$ is the lightning short-circuit current (which is defined as the lightning current that would be measured at an ideally grounded strike object of negligible height), $\rho_{\text {bot }}$ is the current reflection coefficient at the bottom of the strike object, $\rho_{\text {top }}$ is the current reflection coefficient at the top of the strike object for upwardpropagating waves, $n$ is an index representing the successive multiple reflections occurring at the two ends of the strike object, $c$ is the speed of light (current propagation speed along the strike object), and $v$ is the current propagation speed along the channel.

Equations (1a) and (1b) are the same as (10a) and (10b) of Baba and Rakov [18], except that $v_{\text {ref }}$, the speed of current waves reflected from ground and then transmitted into the lightning channel, in (10b) [18] is replaced by $v$ (return-stroke front speed) in (1b). The rationale for replacing $v_{\text {ref }}$ with $v$ is discussed by Baba and Rakov [18]. Equations (1a) and (1b) show that two current waves of the same magnitude, $\left(1-\rho_{\text {top }}\right) I_{\mathrm{sc}}(h, t) / 2$, are initially injected downward, into the strike object, and upward, into the lightning channel.

The current distribution, $I\left(z^{\prime}, t\right)$, along the lightning channel for the case of strike to flat ground, is given by Baba and Rakov [18]

$$
I\left(z^{\prime}, t\right)=\frac{1+\rho_{\mathrm{gr}}}{2} I_{\mathrm{sc}}\left(0, t-\frac{z^{\prime}}{v}\right)
$$

where $I_{\mathrm{sc}}(0, t)$ is the lightning short-circuit current same as $I_{\mathrm{sc}}$ $(h, t)$ in (1a) and (1b), but injected at $z^{\prime}=0$ instead of $\left.z^{\prime}=h\right)$, and $\rho_{\mathrm{gr}}$ is the current reflection coefficient at the channel base (ground). Note that when $h$ approaches zero, (1b) reduces to (2) and (1a) reduces to (2) with $z^{\prime}=0$ [18]. The total charge transfer to ground, i.e., calculated integrated current given by (1a) at $\mathrm{z}^{\prime}=0$, is the same as that calculated integrating current given by (2) at $z^{\prime}=0$ [12]. Therefore, current distributions for the case of strikes to a tall object (1a), (1b) and for the case of strikes to flat ground (2) correspond to the same lightning discharge, as required for examining the influence of the strike object. On the other hand, currents injected into the lightning channel in these two cases are generally different: $I=\left(1-\rho_{\text {top }}\right) I_{\mathrm{sc}} / 2$ versus $I=\left(1+\rho_{\mathrm{gr}}\right) I_{\mathrm{sc}} / 2$, unless $\rho_{\mathrm{top}}=0$ and $\rho_{\mathrm{gr}}=0$ (matched conditions at the position of the source) or $\rho_{\text {top }}=-\rho_{\mathrm{gr}}$ ( $Z_{\mathrm{ob}}=Z_{\mathrm{gr}}$, where $Z_{\mathrm{ob}}$ is the characteristic impedance of the strike object, and $Z_{\mathrm{gr}}$ is the grounding impedance). Both these situations are physically unrealistic, since typically $\rho_{\mathrm{gr}}=$ 1 ( $Z_{\text {gr }} \ll Z_{\text {ob }}$ and $Z_{\text {gr }} \ll Z_{\text {ch }}$, where $Z_{\text {ch }}$ is the equivalent impedance of the lightning channel).

In the FDTD calculations, the lightning channel and the strike object are represented by a vertical array of current sources [22]. Each current source has a length of $10 \mathrm{~m}$ and is described by specifying the four magnetic-field vectors forming a square contour surrounding the cubic cell representing the current source [22]. The lightning short-circuit current $I_{\mathrm{sc}}(h, t)$ or $I_{\mathrm{sc}}$ $(0, t)$ is specified by the current waveform proposed by Nucci et al. [26], which is thought to be typical for lightning subsequent return strokes. The amplitude of this current waveform is $11 \mathrm{kA}$, and the zero-to-peak RT is about $0.5 \mu \mathrm{s}$ (the corresponding 10 -to-90\% RT is $0.15 \mu \mathrm{s})$. The current propagation speed along the channel is set to $v=0.5 c$ (e.g., [27]). The current reflection coefficient at the bottom of the strike object is set to $\rho_{\text {bot }}=1$ ( $Z_{\mathrm{ob}}$ is usually much larger than $\left.Z_{\mathrm{gr}}\right)$, and the current reflection coefficient at the top of the tall object is $\rho_{\text {top }}=-0.5\left(Z_{\mathrm{ch}}=3 Z_{\mathrm{ob}}\right)$. Note that Janischewskyj et al. [28], from their analysis of five current waveforms measured $474 \mathrm{~m}$ above ground on the $\mathrm{CN}$ Tower, inferred $\rho_{\text {top }}$ to vary from -0.27 to -0.49 , and Fuchs [29], from 13 simultaneous current measurements at the top and bottom of the Peissenberg tower, found $\rho_{\text {top }}$ to vary from -0.39 to -0.68 . In the case of lightning strike to flat ground, the current reflection coefficient at the channel base (ground) is set to $\rho_{\mathrm{gr}}=1\left(Z_{\mathrm{ch}} \gg Z_{\mathrm{gr}}\right)$. The assumption of $\rho_{\mathrm{gr}}=1$ is supported by the inference from triggered-lightning 


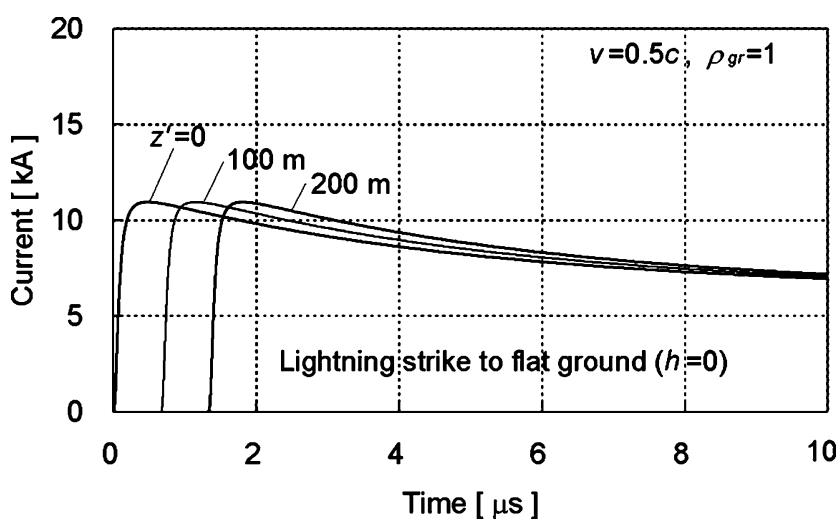

Fig. 2. Current waveforms for a lightning strike to flat ground $(h=0$, $v=0.5 c$, and $\rho_{\mathrm{gr}}=1$ ) at different heights $z^{\prime}=0,100$, or $200 \mathrm{~m}$ along the lightning channel, calculated using (2).

experiments that lightning is capable of lowering its grounding impedance to a value that is always much lower than the equivalent impedance of the lightning channel (e.g., [30] and [31]).

In the following section, we calculate the vertical electric field $E_{z}$ and azimuthal magnetic field $H_{\varphi}$ at three points denoted as points 1-3 shown in Fig. 1: point 2 is located at the center point of the flat roof of the building having a plan area of $S_{b}=40 \times$ $40 \mathrm{~m}^{2}$ (or at the corresponding point on the ground surface in the absence of the building), and points 1 and 3 are located at ground level $70 \mathrm{~m}$ closer to or farther from the lightning strike point than point 2 (points 1 and 3 are each located $50 \mathrm{~m}$ from the nearest wall of the building). Note that $E_{z}$ at ground level (or on the roof of the building) in this paper is averaged from the ground surface (or the roof of the building) to a point $10 \mathrm{~m}$ directly above it due to the use of $10 \times 10 \times 10-\mathrm{m}^{3}$ cubic cells. The variation of $E_{z}$ with height from 0 to $10 \mathrm{~m}$ at the center point of the $40 \times 40-\mathrm{m}^{2}$ flat roof is not significant $\left(E_{z}\right.$ averaged from the roof surface to a point $5 \mathrm{~m}$ directly above it, calculated using the FDTD method with $5 \times 5 \times 5 \mathrm{~m}^{3}$ cubic cells, is only $20 \%$ larger than that averaged from 5 to $10 \mathrm{~m}$ ). The variation of $E_{z}$ with height near corners is more significant. Additionally, there is a significant horizontal component of electric field at the corners.

In Section III-A, we calculate $E_{z}$ and $H_{\varphi}$ at points 1-3 due to a nearby lightning strike to flat ground in the absence of the building and in the presence of the building of height $h_{b}=20$, 50 , and $100 \mathrm{~m}$ at the field point located at horizontal distance $d=100,200$, or $500 \mathrm{~m}$ from the lightning strike point. In Section III-B, we calculate those due to a lightning strike to a tall grounded object of height $h=100,200$, or $500 \mathrm{~m}$. In Section III-C, we examine the influences on $E_{z}$ and $H_{\varphi}$ of the ground conductivity $\sigma_{g}$ and the building conductivity $\sigma_{b}$, the plan area of the building $S_{b}$, and the return-stroke current RT.

\section{ANALYSIS AND RESULTS}

\section{A. Transient Fields Due to Lightning Strikes to Flat Ground in the Presence and Absence of a Building at the Field Point}

Fig. 2 shows current waveforms at different heights $z^{\prime}=0$, 100 , and $200 \mathrm{~m}$, along the lightning channel for a lightning strike

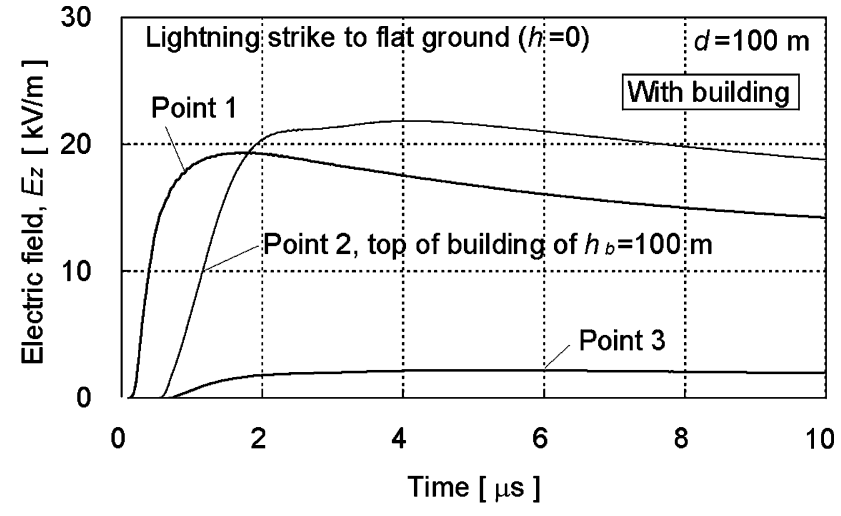

(a)

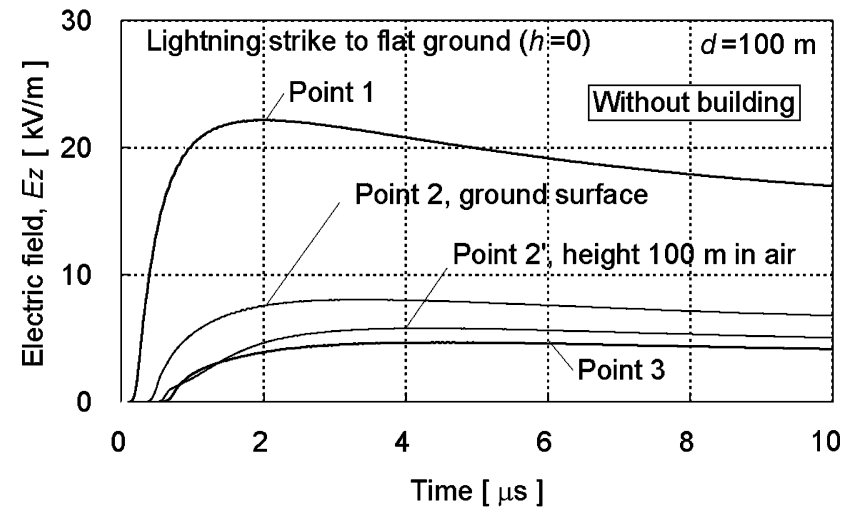

(b)

Fig. 3. (a) Waveforms of vertical electric field $E_{z}$ at points 1-3 (see Fig. 1) due to a lightning strike to flat ground in the presence of a building of $h_{b}=$ $100 \mathrm{~m}$ located at distance $d=100 \mathrm{~m}$ from the strike point, and (b) those in the absence of a building. Additionally shown in (b) is the vertical electric field at point $2^{\prime}$ located at height $100 \mathrm{~m}$ in air directly above point 2 .

to flat ground, calculated using (2). Fig. 3(a) shows resultant waveforms of $E_{z}$ at points 1-3 (see Fig. 1) in the presence of the building of $h_{b}=100 \mathrm{~m}$ located at distance $d=100 \mathrm{~m}$ from the strike point, and Fig. 3(b) shows those in the absence of the building. Fig. 4(a) and (b) is the same as Fig. 3(a) and (b), but for $h_{b}=20 \mathrm{~m}$, while Fig. 5(a) and (b) is the same as Fig. 3(a) and (b), respectively, but for $d=200 \mathrm{~m}$. Fig. 6(a) shows waveforms of $H_{\varphi}$ at points 1-3 in the presence of the building of $h_{b}=100 \mathrm{~m}$ located at distance $d=100 \mathrm{~m}$ from the strike point, and Fig. 6(b) shows those in the absence of the building. Table I contains ratios of magnitudes of vertical electric field $E_{z}$ at points $1-3$ in the presence of the building of height $h_{b}=20,50$, and $100 \mathrm{~m}$ located at distance $d=100,200$, or $500 \mathrm{~m}$ from the strike point and those in the absence of the building $\left(h_{b}=0\right)$. Note that the ratio at point 2 is the ratio of $E_{z}$ on the roof of the building to $E_{z}$ at the same horizontal distance on the ground surface in the absence of the building.

It is clear from comparison of Fig. 3(a) and (b) [or Fig. 5(a) and (b)] that the magnitude of $E_{z}$ on the roof of the building of height $h_{b}=100 \mathrm{~m}$ (point 2) is about a factor of 3 larger than that at the same horizontal distance on the ground surface in 


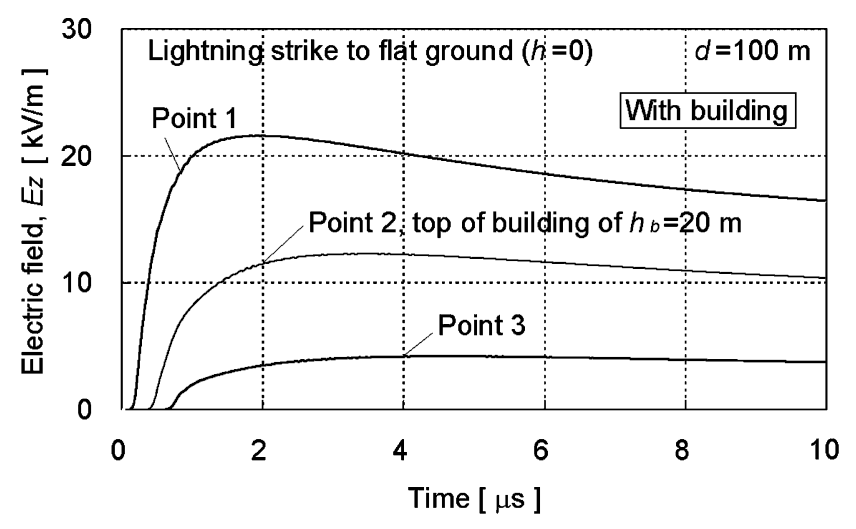

(a)

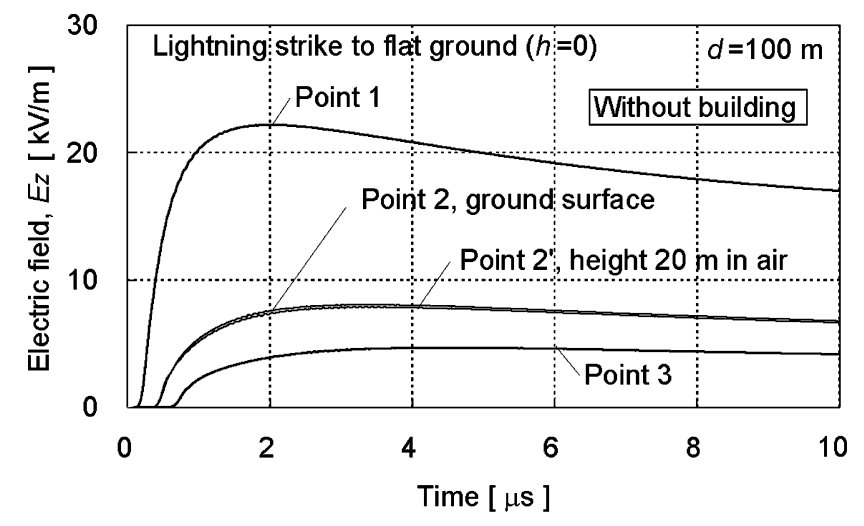

(b)

Fig. 4. (a) Waveforms of vertical electric field $E_{z}$ at points 1-3 (see Fig. 1) due to a lightning strike to flat ground in the presence of a building of $h_{b}=$ $20 \mathrm{~m}$ located at distance $d=100 \mathrm{~m}$ from the strike point, and (b) those in the absence of a building. Additionally shown in (b) is the vertical electric field at point $2^{\prime}$ located at height $100 \mathrm{~m}$ in air directly above point 2 .

the absence of the building, while those at points 1 and 3 in the presence of the building are about 20 and $50 \%$, respectively, smaller than those in the absence of the building. It is also clear from Fig. 6(a) that magnitudes of $H_{\varphi}$ at points 1-3 are not much influenced by the presence of the building of height $h_{b}=100 \mathrm{~m}$ (difference is less than $10 \%$ ). Note that $E_{z}$ and $H_{\varphi}$ at point 2 (ground surface) in the absence of the building are not much different from those at point $2^{\prime}$ (height $100 \mathrm{~m}$ in air directly above point 2). Also note that electric fields, including both vertical and horizontal components, at the corners (at the roof level and closer to the lightning channel) of the building are, within our discretization uncertainty, about two to three times larger than that at point 2 (at the center point of the roof of the building).

It follows from Table I that the magnitude of $E_{z}$ on the roof of the building (point 2) becomes larger as the building height $h_{b}$ increases at horizontal distances $d$ ranging from 100 to $500 \mathrm{~m}$ (the rounded-off ratios are $1.5,2$, and 3 for $h_{b}=20$, 50 , and $100 \mathrm{~m}$, respectively). The dependence of the ratio on the horizontal distance $d$ of the building from the strike point is weak. We also estimated (see Appendix B) the values of static electric-field enhancement factor due to the presence of a

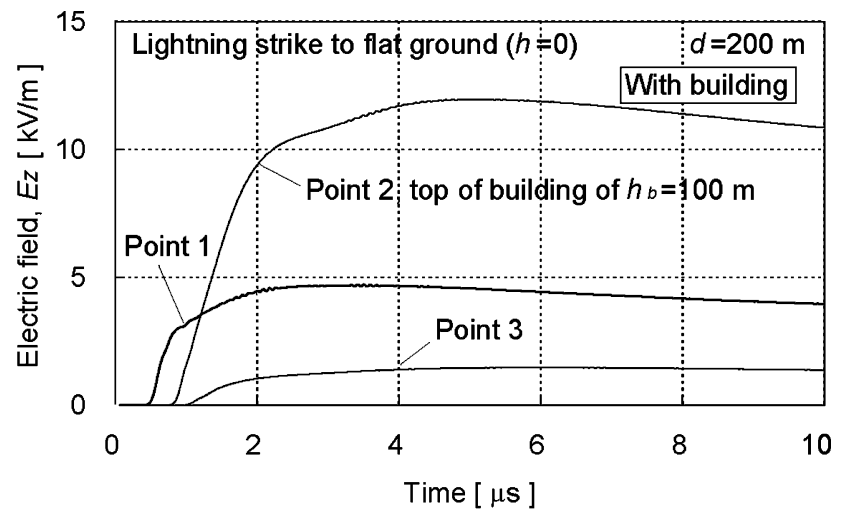

(a)

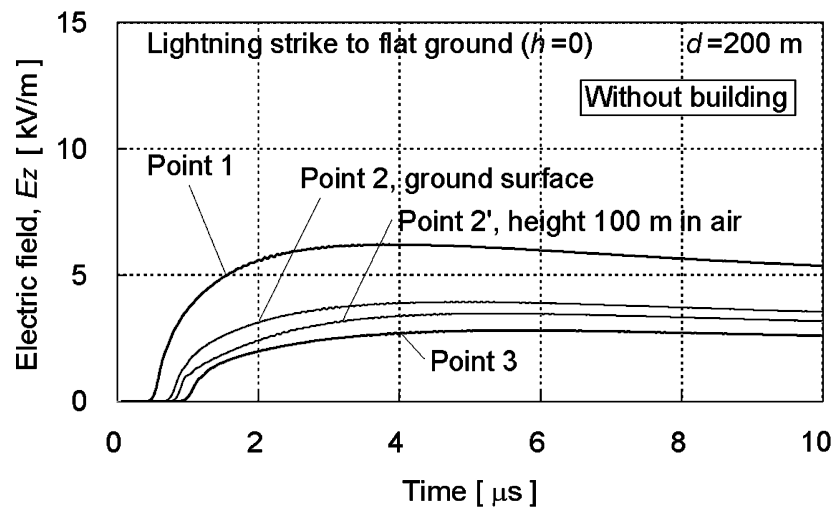

(b)

Fig. 5. (a) Waveforms of vertical electric field $E_{z}$ at points 1-3 (see Fig. 1) due to a lightning strike to flat ground in the presence of a building of $h_{b}=$ $100 \mathrm{~m}$ located at distance $d=200 \mathrm{~m}$ from the strike point, and (b) those in the absence of a building. Additionally shown in (b) is the vertical electric field at point $2^{\prime}$ located at height $100 \mathrm{~m}$ in air directly above point 2 .

perfectly conducting building of plan area $S_{b}=40 \times 40 \mathrm{~m}^{2}$ and height $h_{b}=20,50$, or $100 \mathrm{~m}$ and found that they are essentially the same as their transient (lightning-related) counterparts.

It is of interest to compare the enhancement factors of buildings with the enhancement factors of half-ellipsoids of similar overall dimensions, for which analytical expressions are available in the literature (e.g., [15, eq. (4.1)]). Note that the analytical expressions for the enhancement factors of half-ellipsoids were developed for uniform static, not transient electric fields. We will assume that the semiminor (horizontal) axis of the ellipsoid, placed on a ground plane, is equal to $20 \mathrm{~m}$ and the semimajor (vertical) axis is either 50 or $100 \mathrm{~m}$. The corresponding static electric-field enhancement factors at the highest point of ellipsoid are 7 and 18, considerably larger than 2 and 3 for rectangular buildings of the same height and similar plan area at the ground surface. For a hemisphere on ground, the enhancement factor is 3 at its highest point (e.g., [32]), which is a factor of 2 larger than 1.5 found in this study for a $40 \times 40 \times$ $20 \mathrm{~m}^{3}$ rectangular building. Clearly, the curved surface of ellipsoid (or hemisphere) is more efficient in concentrating electricfield lines compared to the flat roof of a rectangular building of similar overall dimensions (see also Fig. 11). 


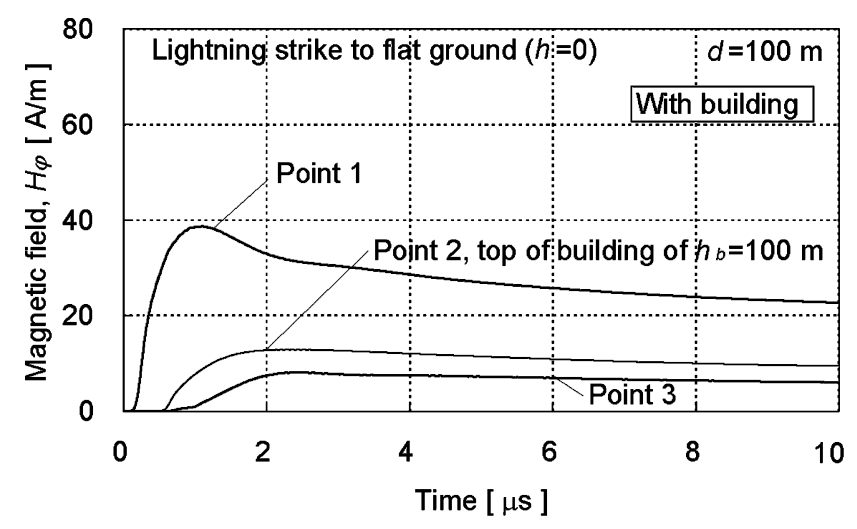

(a)

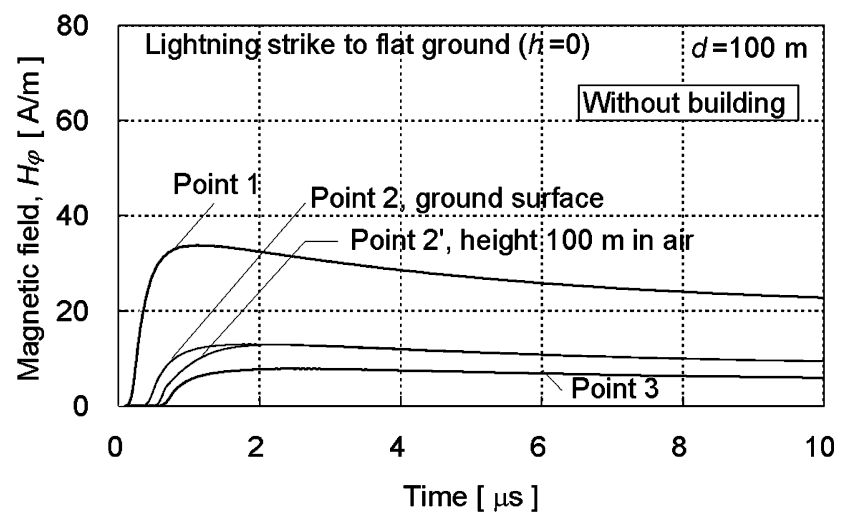

(b)

Fig. 6. (a) Waveforms of azimuthal magnetic field $H_{\varphi}$ at points 1-3 (see Fig. 1) due to a lightning strike to flat ground in the presence of a building of $h_{b}=100 \mathrm{~m}$ located at distance $d=100 \mathrm{~m}$ from the strike point, and (b) those in the absence of a building. Additionally shown in (b) is the vertical electric field at point $2^{\prime}$ located at height $100 \mathrm{~m}$ in air directly above point 2 .

The magnitudes of $E_{z}$ at ground level in the vicinity of the building (both in front of the building, point 1, and behind the building, point 3 ) become smaller as $h_{b}$ increases. Note that the magnitude of $E_{z}$ at ground level by the side of the building (not presented in this paper) also becomes smaller with increasing $h_{b}$. As expected, reduction of $E_{z}$ behind the building is largest, that in front of it is smallest, and that by the side of it is intermediate. In each case, reduction of $E_{z}$ at ground level due to the presence of building is negligible (less than 10\%) at horizontal distances from the building that are more than twice the building height.

The observed effects can be explained as follows. A conducting object protruding above ground level in an external electric field (transient or static) having a vertical component facilitates motion of electric charges to its upper extremity and thereby serves to enhance the vertical electric field component there. On the other hand, the boundary condition on the vertical electric field on vertical conducting surfaces (e.g., walls of a rectangular building) requires that the field is nearly zero on the surface and reduced in their vicinity. The motion of charges constitutes current in the conducting object, but the magnetic field associ-
TABLE I

Ratios of Magnitudes of Vertical Electric Field $E_{z}$ AT Points 1-3 (SEE Fig. 1) Due to A Lightning StRIKe TO Flat GROUND $(h=0)$ IN THE PRESENCE OF A BuILdING OF HEIGHT $h_{b}=20,50$, OR $100 \mathrm{~m}$ AT THE FIELd POINT, LOCATED AT HorizONTAL DistanCE OF $d=100,200$, OR $500 \mathrm{~m}$ FROM THE LIGHTNING STRIKE POINT AND THOSE IN THE ABSENCE OF THE BUILDING $\left(h_{b}=0\right)$

\begin{tabular}{l|c|ccc}
\hline \multirow{2}{*}{ Field point } & \multirow{2}{*}{$\begin{array}{c}\text { Horizontal } \\
\text { distance, } d, \mathrm{~m}\end{array}$} & \multicolumn{3}{|c}{ Building height, $h_{b}, \mathrm{~m}$} \\
\cline { 3 - 5 } & 100 & 20 & 50 & 100 \\
\hline Point 1, & 200 & 0.95 & 0.94 & 0.88 \\
$\begin{array}{l}\text { on ground } \\
\text { in front of }\end{array}$ & 500 & 0.96 & 0.82 & 0.77 \\
building & 100 & $\mathbf{1 . 5}$ & $\mathbf{2 . 1}$ & $\mathbf{2 . 7}$ \\
\hline $\begin{array}{l}\text { Point 2, } \\
\text { on roof of } \\
\text { building }\end{array}$ & 200 & $\mathbf{1 . 5}$ & $\mathbf{2 . 2}$ & $\mathbf{3 . 0}$ \\
\hline $\begin{array}{l}\text { Point 3, } \\
\text { on ground } \\
\text { behind }\end{array}$ & 500 & $\mathbf{1 . 5}$ & $\mathbf{2 . 2}$ & $\mathbf{3 . 2}$ \\
\hline building & 100 & 0.90 & 0.69 & 0.46 \\
\hline
\end{tabular}

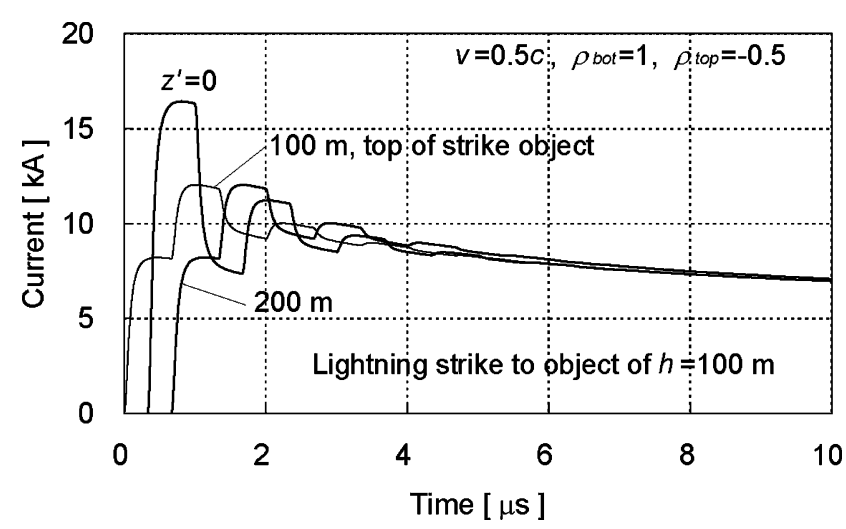

Fig. 7. Current waveforms for a lightning strike to tall object of height $h=$ $100 \mathrm{~m}\left(v=0.5 c, \rho_{\text {bot }}=1\right.$, and $\left.\rho_{\text {top }}=-0.5\right)$ at different heights $z^{\prime}=0$ (bottom of the strike object), $100 \mathrm{~m}$ (top of the strike object), or $200 \mathrm{~m}$ (100 m above the top of the strike object), calculated using (1a) and (1b).

ated with this current has relatively little effect on the incident magnetic field.

\section{B. Transient Fields Due to Lightning Strikes to a Tall Object in the Presence and Absence of a Building at the Field Point}

Fig. 7 shows current waveforms for a lightning strike to tall object of height $h=100 \mathrm{~m}$ at different heights above ground $z^{\prime}=0$ (bottom of the strike object), $100 \mathrm{~m}$ (top of the strike object), and $200 \mathrm{~m}$ (100 $\mathrm{m}$ above the top of the strike object), calculated using (1a) and (1b). Fig. 8(a) shows waveforms of $E_{z}$ at points 1-3 due to a lightning strike to an object of height $h=$ $100 \mathrm{~m}$ in the presence of the building of $h_{b}=100 \mathrm{~m}$ at the field point located at distance $d=100 \mathrm{~m}$ from the strike point, and Fig. 8(b) shows those in the absence of the building. Fig. 9(a) shows waveforms of $H_{\varphi}$ at points 1-3 due to a lightning strike to an object of height $h=100 \mathrm{~m}$ in the presence of the building of $h_{b}=100 \mathrm{~m}$ located at distance $d=100 \mathrm{~m}$ from the strike 


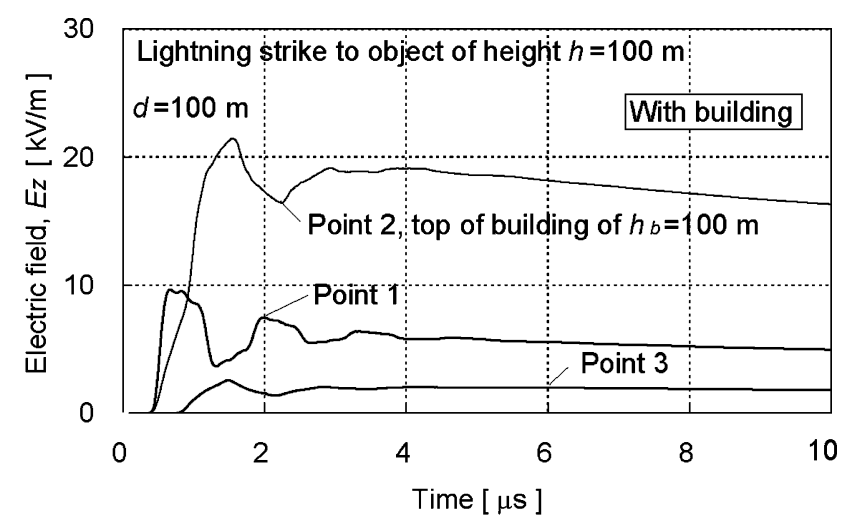

(a)

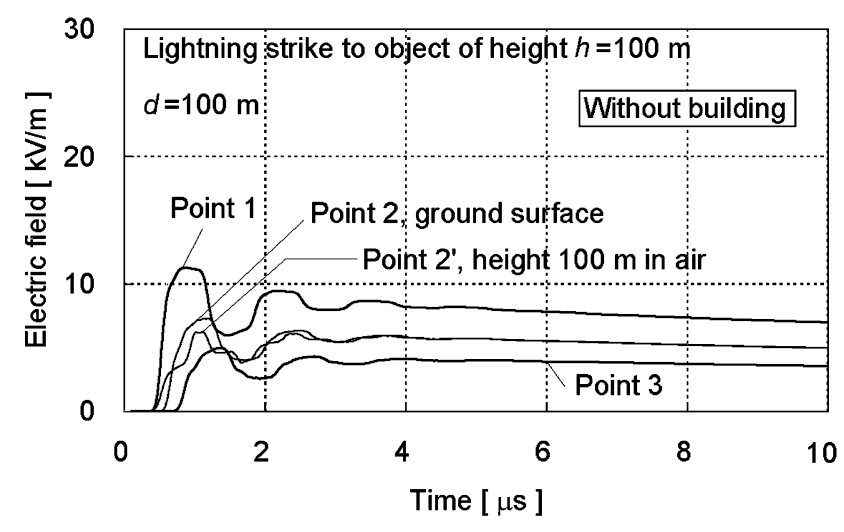

(b)

Fig. 8. (a) Waveforms of vertical electric field $E_{z}$ at points 1-3 due to a lightning strike to grounded object of height $h=100 \mathrm{~m}$ in the presence of building of $h_{b}=100 \mathrm{~m}$ located at distance $d=100 \mathrm{~m}$ from the strike object, and (b) those in the absence of a building (point $2^{\prime}$ is located at height $100 \mathrm{~m}$ in air directly above point 2 ).

point, and Fig. 9(b) shows those in the absence of the building. Table II shows the ratios of magnitudes of vertical electric field $E_{z}$ at points 1-3 due to a lightning strike to a grounded object of height $h=100 \mathrm{~m}$ in the presence of the building of height $h_{b}=$ 20,50 , or $100 \mathrm{~m}$ located at distance $d=100,200$, or $500 \mathrm{~m}$ from the strike object and those in the absence of the building $\left(h_{b}=\right.$ $0)$. Similar to the configuration discussed in Section III-A, the ratio at point 2 is the ratio of $E_{z}$ on the roof of the building to $E_{z}$ at the same horizontal distance on the ground surface in the absence of the building. Tables III and IV are similar to Table II, but for $h=200$ and $500 \mathrm{~m}$, respectively.

It is clear from comparison of Fig. 8(a) and (b) that the magnitude of $E_{z}$ on the roof of the building of height $h_{b}=100 \mathrm{~m}$ (point 2) is about a factor of 2.9 larger than that at the same horizontal distance on the ground surface in the absence of the building, while those at points 1 and 3 in the presence of building are about 10 and $50 \%$, respectively, smaller than those in the absence of the building. It is also seen in Fig. 9(a) and (b) that magnitudes of $H_{\varphi}$ at points 1-3 are not significantly influenced by the presence of the building of height $h_{b}=100 \mathrm{~m}$ (difference is less than 20\%). Similar to the configuration discussed in Section III-A, $E_{z}$ and $H_{\varphi}$ at point 2 (ground surface) in the

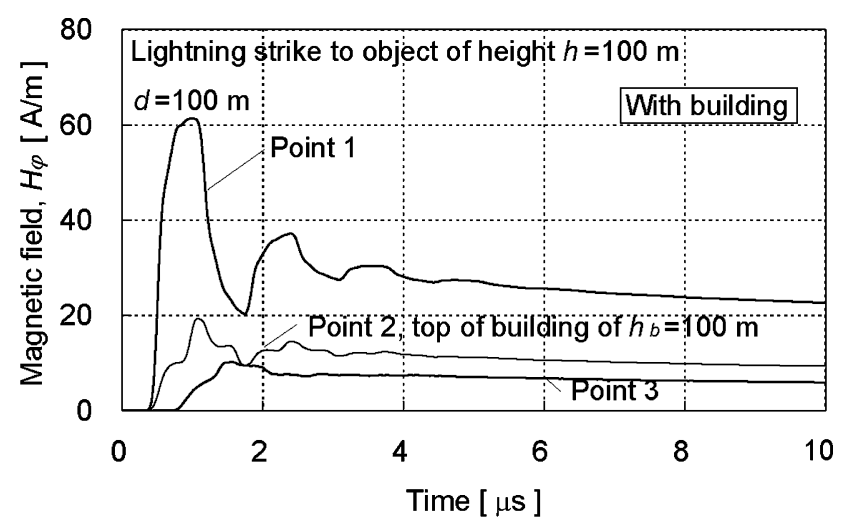

(a)

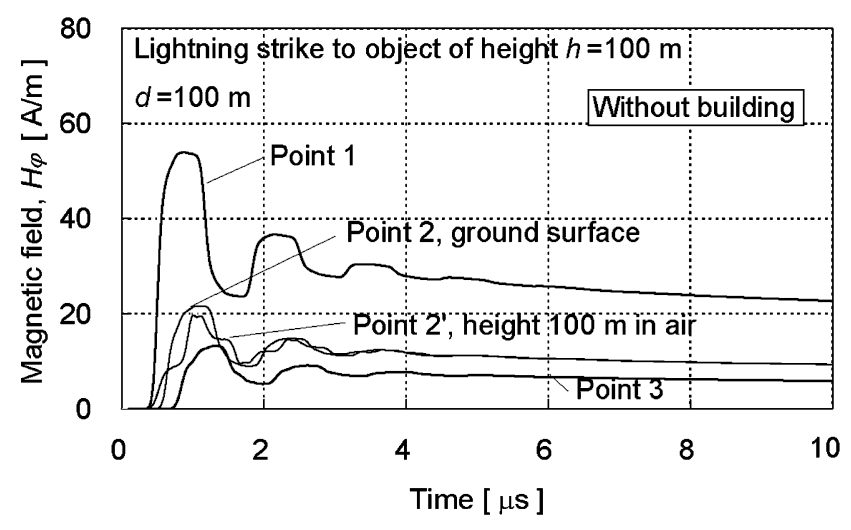

(b)

Fig. 9. (a) Waveforms of azimuthal magnetic field $H_{\varphi}$ at points 1-3 due to a lightning strike to grounded object of height $h=100 \mathrm{~m}$ in the presence of a building of $h_{b}=100 \mathrm{~m}$ located at distance $d=100 \mathrm{~m}$ from the strike object, and (b) those in the absence of a building (point $2^{\prime}$ is located at height $100 \mathrm{~m}$ in air directly above point 2 ).

TABLE II

Ratios of Magnitudes of Vertical EleCtric Field $E_{z}$ AT Points 1-3 (SEe Fig. 1) Due to A Lightning StRike to a 100-m TAll OBJect $(h=100 \mathrm{~m})$ IN THE PRESENCE OF A BUILDING OF HEIGHT

$h_{b}=20,50$, OR $100 \mathrm{~m}$ AT THE FIELD POINT, LOCATED AT HORIZONTAL DistANCE $d=100,200$, OR $500 \mathrm{~m}$ FROM THE LiGHTNING STRIKE POINT AND THOSE IN THE ABSENCE OF THE BUILDING $\left(h_{b}=0\right)$

\begin{tabular}{l|c|ccc}
\hline \multirow{2}{*}{ Field point } & \multirow{2}{*}{$\begin{array}{c}\text { Horizontal } \\
\text { distance, } d, \mathrm{~m}\end{array}$} & \multicolumn{3}{|c}{ Building height, $h_{b}, \mathrm{~m}$} \\
\cline { 3 - 5 } & 100 & 20 & 50 & 100 \\
\hline Point 1, & 200 & 0.96 & 0.89 & 0.87 \\
$\begin{array}{l}\text { on ground } \\
\text { in front of } \\
\text { building }\end{array}$ & 500 & 0.95 & 0.86 & 0.79 \\
\hline $\begin{array}{l}\text { Point 2, } \\
\text { on roof of } \\
\text { building }\end{array}$ & 100 & $\mathbf{1 . 6}$ & $\mathbf{2 . 3}$ & $\mathbf{2 . 9}$ \\
\hline $\begin{array}{l}\text { Point 3, } \\
\text { on ground } \\
\text { behind }\end{array}$ & 200 & $\mathbf{1 . 6}$ & $\mathbf{2 . 3}$ & $\mathbf{2 . 8}$ \\
building & 500 & $\mathbf{1 . 6}$ & $\mathbf{2 . 4}$ & $\mathbf{2 . 9}$ \\
\hline
\end{tabular}


TABLE III

Ratios of Magnitudes of Vertical Electric Field $E_{z}$ AT Points 1-3 (SEe Fig. 1) Due to a Lightning StRiKe to a 200-m TAll ObJeCt $(h=200 \mathrm{~m})$ IN THE PRESENCE OF A BUILDING OF HEIGHT $h_{b}=20,50$, OR $100 \mathrm{~m}$ AT THE FIELD POINT, LOCATED AT HORIZONTAL DistancE $d=100,200$, OR $500 \mathrm{~m}$ FrOM THE LightNING STRIKE POINT AND THOSE IN THE ABSENCE OF THE BUILDING $\left(h_{b}=0\right)$

\begin{tabular}{l|c|ccc}
\hline \multirow{2}{*}{ Field point } & Horizontal & \multicolumn{3}{|c}{ Building height, $h_{b}, \mathrm{~m}$} \\
\cline { 3 - 5 } & distance, $d, \mathrm{~m}$ & 20 & 50 & 100 \\
\hline Point 1, & 100 & 0.94 & 0.90 & 0.89 \\
$\begin{array}{l}\text { on ground } \\
\text { in front of } \\
\text { building }\end{array}$ & 200 & 0.95 & 0.86 & 0.79 \\
\hline $\begin{array}{l}\text { Point 2, } \\
\text { on roof of } \\
\text { building }\end{array}$ & 500 & 0.96 & 0.84 & 0.73 \\
\hline $\begin{array}{l}\text { Point 3, } \\
\text { on ground }\end{array}$ & 100 & $\mathbf{1 . 6}$ & $\mathbf{2 . 5}$ & $\mathbf{3 . 8}$ \\
behind & 500 & $\mathbf{1 . 6}$ & $\mathbf{2 . 4}$ & $\mathbf{3 . 6}$ \\
building & 100 & $\mathbf{1 . 6}$ & $\mathbf{2 . 3}$ & $\mathbf{3 . 6}$ \\
\hline
\end{tabular}

TABLE IV

Ratios of Magnitudes of Vertical Electric Field $E_{z}$ AT Points 1-3 (SEe Fig. 1) DUe to A LightNing STRIKE TO A 500-m TALl OBJECT $(h=500 \mathrm{~m})$ IN THE PRESENCE OF A BUILDING OF HEIGHT $h_{b}=20,50$, OR $100 \mathrm{~m}$ AT THE FIELD POINT, LOCATED AT HORIZONTAL DisTANCE $d=100,200$, OR $500 \mathrm{~m}$ FROM THE LIGHTNING STRIKE POINT AND THOSE IN THE ABSENCE OF THE BUILDING $\left(h_{b}=0\right)$

\begin{tabular}{l|c|ccc}
\hline \multirow{2}{*}{ Field point } & \multirow{2}{*}{$\begin{array}{c}\text { Horizontal } \\
\text { distance, } d, \mathrm{~m}\end{array}$} & \multicolumn{3}{|c}{ Building height, $h_{b}, \mathrm{~m}$} \\
\cline { 3 - 5 } & 100 & 0.96 & 0.96 & 0.97 \\
\hline Point 1, & 200 & 0.98 & 0.91 & 0.83 \\
$\begin{array}{l}\text { on ground } \\
\text { in front of }\end{array}$ & 500 & 0.94 & 0.85 & 0.73 \\
$\begin{array}{l}\text { building } \\
\text { Point 2, }\end{array}$ & 100 & $\mathbf{1 . 6}$ & $\mathbf{2 . 3}$ & $\mathbf{3 . 3}$ \\
$\begin{array}{l}\text { on roof of } \\
\text { building }\end{array}$ & 200 & $\mathbf{1 . 5}$ & $\mathbf{2 . 3}$ & $\mathbf{3 . 4}$ \\
\hline $\begin{array}{l}\text { Point 3, } \\
\text { on ground }\end{array}$ & 500 & $\mathbf{1 . 6}$ & $\mathbf{2 . 2}$ & $\mathbf{3 . 4}$ \\
$\begin{array}{l}\text { behind } \\
\text { building }\end{array}$ & 100 & 0.96 & 0.77 & 0.58 \\
\hline
\end{tabular}

absence of building are not much different from those at point $2^{\prime}$ (height $100 \mathrm{~m}$ in air right above point 2).

It follows from Tables II-IV that the magnitude of $E_{z}$ on the roof of the building (point 2) becomes larger as the building height $h_{b}$ increases for horizontal distances $d$ ranging from 100 to $500 \mathrm{~m}$, while the magnitudes of $E_{z}$ at ground level in the vicinity of the building become smaller with increasing $h_{b}$. The dependence of the ratio on horizontal distance $d$ between the building and the strike object is weak, as is that on the strikeobject height $h$. The ratios are 1.6, 2.3, and 3-4 for $h_{b}=20,50$, and $100 \mathrm{~m}$, respectively, which are almost the same as those in
TABLE V

Peak Values of $E_{z}$ IN Kilovolts PeR Meter on the Roof of a Building (POINT 2 IN Fig. 1) OF HEIGHT $h_{b}=100 \mathrm{~m}$ LOCATED AT DisTANCE $d=100$ m From Strike ObJect of Height $h=0$ (Strike to Flat Ground), 100, 200, OR $500 \mathrm{~m}$, AND THOSE AT THE SAME HoRIZONTAL DistaNCE ON THE GROUND SURFACE IN THE ABSENCE OF THE BUILDING $\left(h_{b}=0\right)$

\begin{tabular}{c|c|c|c}
\hline $\begin{array}{c}\text { Strike object } \\
\text { height, } h, \mathrm{~m}\end{array}$ & $\begin{array}{c}\text { E-field on building } \\
\text { roof, } \mathrm{kV} / \mathrm{m}\end{array}$ & $\begin{array}{c}\text { E-field at ground } \\
\text { surface, } \mathrm{kV} / \mathrm{m}\end{array}$ & Ratio \\
\hline 0 & 22 & 8.1 & 2.7 \\
100 & 22 & 7.5 & 2.9 \\
200 & 20 & 5.3 & 3.8 \\
500 & 9.8 & 3.0 & 3.3 \\
\hline
\end{tabular}

TABLE VI

RATIOS OF MAGNitudes OF Vertical ElECTRIC FIELD $E_{z}$ ON THE ROOF OF A BuILDING OF HEIGHT $h_{b}=100 \mathrm{~m}$ DUE TO A LightNing STRIKe to Flat GROUND AND THOSE IN THE ABSENCE OF THE BUILDING $\left(h_{b}=0\right)$, CALCULATED FOR DIFFERENT SETS OF GROUND CONDUCTIVITY, $\sigma_{g}$, AND BUILDING CONDUCTIVITY, $\sigma_{b}$

\begin{tabular}{|c|c|c|c|c|}
\hline \multirow{2}{*}{$\begin{array}{c}\text { Ground } \\
\text { conductivity, } \\
\sigma_{\mathrm{g}}, \mathrm{mS} / \mathrm{m}\end{array}$} & \multirow{2}{*}{$\begin{array}{c}\text { Building } \\
\text { conductivity, } \\
\sigma_{b}, \mathrm{mS} / \mathrm{m}\end{array}$} & \multicolumn{3}{|c|}{$\begin{array}{l}\text { Horizontal distance, } \\
\qquad d, \mathrm{~m}\end{array}$} \\
\hline & & 100 & 200 & 500 \\
\hline$\infty$ & $\infty$ & 2.8 & 3.0 & 3.2 \\
\hline$\infty$ & 1 & 2.7 & 3.0 & 3.2 \\
\hline 1 & $\infty$ & 2.7 & 3.0 & 3.2 \\
\hline 1 & 1 & 2.7 & 3.0 & 3.2 \\
\hline 1 & 0.01 & 1.8 & 2.1 & 2.3 \\
\hline
\end{tabular}

the case of lightning strike to flat ground ( $h=0$, see Table I). It is important to note that the magnitude of $E_{z}$ in the vicinity of the strike object decreases with increasing the strike-object height $h$ due to the electric-field reduction effect of the strike object (e.g., [12]), as seen in Table $\mathrm{V}$, although the ratios are not much influenced by $h$.

\section{Influences of the Conductivity of Ground and Building, the Plan Area of the Building, and the RT of Return-Stroke Current}

In the preceding sections, we have calculated fields assuming both the ground conductivity $\sigma_{g}$ and the building conductivity $\sigma_{b}$ to be $1 \mathrm{mS} / \mathrm{m}$, the plan area of the building $S_{b}$ to be $40 \times$ $40 \mathrm{~m}^{2}$, and the 10 -to- $90 \% \mathrm{RT}$ of the return-stroke current to be $0.15 \mu \mathrm{s}$. In this section, we investigate influences of these assumptions on the computed fields.

Table VI shows ratios of magnitudes of $E_{z}$ on the roof of the building of height $h_{b}=100 \mathrm{~m}$ due to a lightning strike to flat ground and those in the absence of the building $\left(h_{b}=0\right)$, calculated for different sets of $\sigma_{g}$ and $\sigma_{b}$. It follows from Table VI that the ratio of electric-field enhancement due to the presence of the building is only slightly influenced by the increase in $\sigma_{g}$ and/or $\sigma_{b}$ from $1 \mathrm{mS} / \mathrm{m}$ to infinity. It is generally known that lightning-generated vertical electric field on/above ground is insensitive to the value of the ground conductivity. When the 
TABLE VII

Ratios of Magnitudes of Vertical Electric Field $E_{z}$ Due to A LIGHTNING STRIKE TO FLAT GROUND ON THE ROOF OF A BUILDING OF HEIGHT $h_{b}=100 \mathrm{~m}$ AND PLAN AREA $S_{b}=20 \times 20$ OR $40 \times 40 \mathrm{~m}^{2}$, LOCATED AT DistancE $d=100,200$, OR $500 \mathrm{~m}$ From the STRIKE POINT, AND THOSE AT THE GROUND SURFACE IN THE ABSENCE OF THE BUILDING $\left(h_{b}=0\right)$

\begin{tabular}{c|ccc}
\hline Building plan area, & \multicolumn{3}{|c}{ Horizontal distance, $d, \mathrm{~m}$} \\
\cline { 2 - 4 }$S_{b}, \mathrm{~m}^{2}$ & 100 & 200 & 500 \\
\hline $20 \times 20$ & 3.4 & 3.7 & 3.9 \\
$40 \times 40$ & 2.7 & 3.0 & 3.2 \\
\hline
\end{tabular}

conductivity of the building is very poor $\left(\sigma_{b}=0.01 \mathrm{mS} / \mathrm{m}\right)$, the ratio becomes about $30 \%$ smaller than that in the case of moderate $(1 \mathrm{mS} / \mathrm{m})$ or perfect conductivity. The ratio of magnitudes of $E_{z}$ on the roof of the building of height $h_{b}=100 \mathrm{~m}$ and that in the absence of the building for $\sigma_{b}=1 \mathrm{mS} / \mathrm{m}$ is 3.0 for both $\varepsilon_{\mathrm{rb}}=1$ and $\varepsilon_{\mathrm{rb}}=10$. When $\sigma_{b}=0.01 \mathrm{mS} / \mathrm{m}$, it is 2.2 for $\varepsilon_{\mathrm{rb}}=1$ and 2.1 for $\varepsilon_{\mathrm{rb}}=10$. Thus, the influence of $\varepsilon_{\mathrm{rb}}$ is small relative to that of $\sigma_{b}$.

Table VII shows the dependence of $E_{z}$ on $S_{b}$. When $S_{b}$ is $20 \times 20 \mathrm{~m}^{2}, E_{z}$ on the roof of the building becomes about $20 \%$ larger than that on the roof of the building of $S_{b}=40 \times 40 \mathrm{~m}^{2}$. This tendency is expected, since, in general, the electric field normal to the conductor surface increases with decreasing the radius (actual or effective) of curvature of the conductor.

The ratio of $E_{z}$ due to a lightning strike to flat ground in the presence of the building of height $h_{b}=100 \mathrm{~m}$ and that at the same horizontal distance on the ground surface in the absence of the building $\left(h_{b}=0\right)$ for $\mathrm{RT}=1.4 \mu \mathrm{s}$, is almost the same as that for RT $=0.15 \mu \mathrm{s}$. The magnitudes of $E_{z}$ both on the roof of the building and at the ground surface in the absence of the building, calculated for $\mathrm{RT}=1.4 \mu \mathrm{s}$, are about $10 \%$ smaller than those calculated for $\mathrm{RT}=0.15 \mu \mathrm{s}$.

When a Gaussian-shape current pulse having a half-peak width of $0.3 \mu \mathrm{s}$ is employed instead of the current waveform characteristic of subsequent return-stroke current, the ratio is $1.5,1.9$, and 2.1 for $h_{b}=20,50$, and $100 \mathrm{~m}$, respectively, regardless of $d$. These ratio values are to be compared with 1.5, 2, and 3 , respectively, found for the lightning return-stroke current waveform.

\section{SUMMARY}

We have compared the vertical electric field $E_{z}$ and azimuthal magnetic field $H_{\varphi}$ due to lightning strikes to a tall object and to flat ground in the presence of the building at the field point with their counterparts in the absence of the building. The magnitude of $H_{\varphi}$ is not much influenced by the presence of either building at the field point or the strike object, while the magnitude of $E_{z}$ on the roof of the building of height $h_{b}=20,50$, or $100 \mathrm{~m}$ is about $1.5,2$, or 3 times, respectively, greater than that at the same horizontal distance on the ground surface in the absence of the building. Dependences of electric-field enhancement factor, due to the presence of the building, on the horizontal distance $d$ (ranging from 100 to $500 \mathrm{~m}$ ) of the building from the lightning channel, on the strike-object height $h$ (ranging from 0 to $500 \mathrm{~m}$ ), on the conductivities of ground $\sigma_{g}$ (ranging from $1 \mathrm{mS} / \mathrm{m}$ to infinity) and the building $\sigma_{b}$ (ranging from $0.01 \mathrm{mS} / \mathrm{m}$ to infinity), and on the 10-to-90\% RT of return-stroke current (from 0.15 to $1.4 \mu \mathrm{s}$ ) are weak. Transient (lightning-related) electric-field enhancement factor due to the presence of the building is similar to the corresponding static-field enhancement factor. The magnitude of $E_{z}$ at ground level in the immediate vicinity of the building is reduced relative to the case of no building, with this shielding effect becoming negligible at horizontal distances from the building greater than twice the height of the building.

\section{APPENDIX A}

\section{COMPARISON OF FIELDS IN THE ABSENCE OF BUILDING COMPUTED USING THE FDTD METHOD AND \\ THOTTAPPILLIL ET AL.'s [19] ANALYTICAL EXPRESSIONS}

In this Appendix, we compare waveshapes and magnitudes of the vertical electric field $E_{z}$ and azimuthal magnetic field $H_{\varphi}$ at the ground surface due to a vertical lightning strike to flat perfectly conducting ground calculated using the FDTD method with corresponding fields calculated using exact analytical expressions derived by Thottappillil et al. [19]. These latter expressions are valid for the TL model, vertical lightning channel terminating on flat, perfectly conducting ground, and return-stroke front speed equal to the speed of light $(v=c)$. Under these conditions, a spherical TEM wave (centered at the channel base) is formed.

In the FDTD procedure, we used the distribution of current along the lightning channel (2000 $\mathrm{m}$ in length, although this is immaterial, because our representation of channel by an array of current sources does not include reflections from the top of the channel) given by (2) with $v=c$ and $\rho_{\mathrm{gr}}=1$, which was represented by a vertical array of current sources, as described in Section II. The lightning short-circuit current $I_{\mathrm{sc}}(0, t)$ was the same as that proposed by Nucci et al. [26]. The peak of this current waveform is $11 \mathrm{kA}$, and the 10 -to-90\% RT is $0.15 \mu \mathrm{s}$.

Thottappillil et al.'s [19] analytical expressions for $E_{z}$ and $H_{\varphi}$ on the ground surface at distance $d$ from the lightning channel are reproduced as follows:

$$
\begin{aligned}
& E_{z}(d, t)=\frac{I(0, t-d / c)}{2 \pi \varepsilon_{0} c d} \\
& H_{\varphi}(d, t)=\frac{I(0, t-d / c)}{2 \pi d} .
\end{aligned}
$$

Note that (A1) gives the exact total electric field, which is the sum of the electrostatic, induction, and radiation components, and (A2) gives the exact total magnetic field, which is the sum of the induction and radiation components [19]; i.e., they are not far-field approximations as they may appear to be.

Fig. 10(a) and (b) shows waveforms of $E_{z}$ and $H_{\varphi}$ at distances $d=50,100,200$, and $500 \mathrm{~m}$ calculated using the FDTD method and exact (A1) and (A2). Table VIII shows peaks of $E_{z}$ and $H_{\varphi}$ at distances $d=50,100,200$, and $500 \mathrm{~m}$ calculated using these two approaches. It follows from Fig. 10 and Table VIII that both waveforms and peaks of $E_{z}$ and $H_{\varphi}$ calculated using these two approaches are in good agreement: the difference in field peaks is less than $3 \%$ at all the distances considered. 


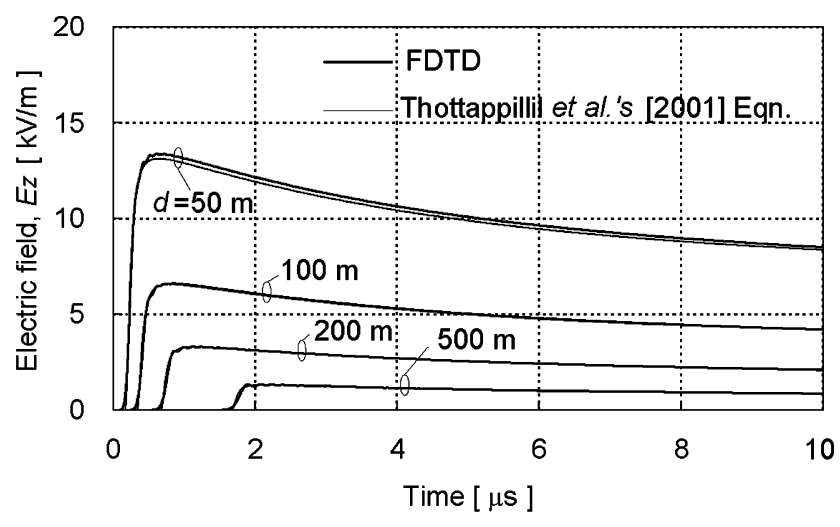

(a)

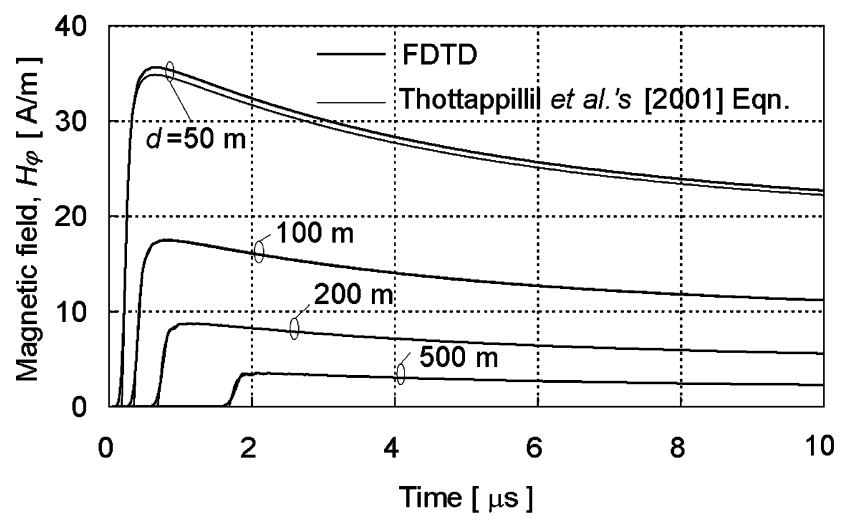

(b)

Fig. 10. (a) Waveforms of vertical electric field $E_{z}$ at horizontal distances $d=50,100,200$, or $500 \mathrm{~m}$ due to a lightning strike to flat perfectly conducting ground calculated for the case of $v=c$ using the FDTD method and Thottappillil et al.'s [19] exact analytical expressions, and (b) those of azimuthal magnetic field $H_{\varphi}$. Lightning short-circuit current waveform, $I_{\mathrm{Sc}}$, having a peak of $11 \mathrm{kA}$ was used.

\section{APPENDIX B}

\section{ENHANCEMENT FACTORS DUE TO THE PRESENCE OF HEMISPHERE OR RECTANGULAR BUILDING IN UNIFORM STATIC ELECTRIC FIELD}

In this Appendix, we compare the value of FDTD-calculated static electric-field enhancement factor due to the presence of a perfectly conducting discretized hemisphere placed on a flat perfectly conducting plane in a uniform vertical electric field with its theoretical value equal to 3 (e.g., [32]). Also, we present FDTD-calculated values of static electric-field enhancement factor for buildings of height $h_{b}=20,50$, and $100 \mathrm{~m}$.

Fig. 11(a) shows a perfectly conducting hemisphere of radius $100 \mathrm{~m}$ on a perfectly conducting plane in a uniform electric field. The enhancement factor for vertical electric field at the top of the hemisphere is known from theory and is equal to 3 (e.g., [32]). Fig. 11(b) and (c) shows a perfectly conducting staircase approximation to hemisphere of radius $100 \mathrm{~m}$ and a perfectly conducting rectangular parallelepiped of height $h_{b}=$ $100 \mathrm{~m}$ and plan area $S_{b}=200 \times 200 \mathrm{~m}^{2}$, both discretized using $10 \times 10 \times 10 \mathrm{~m}^{3}$ cubic cells for FDTD calculations. The discretized hemisphere and rectangular parallelepiped were placed on and in the middle of a $2000 \times 2000 \mathrm{~m}^{2}$ horizontal perfectly

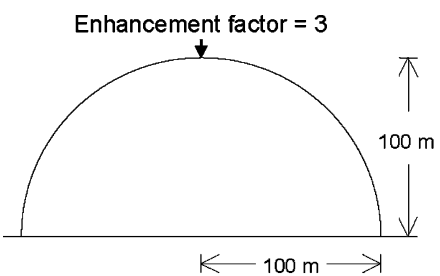

(a)

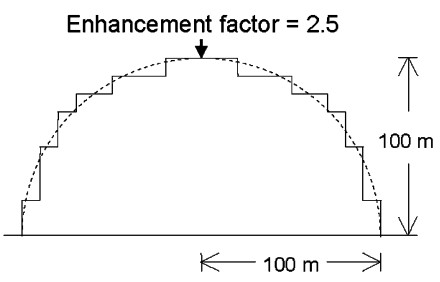

(b)

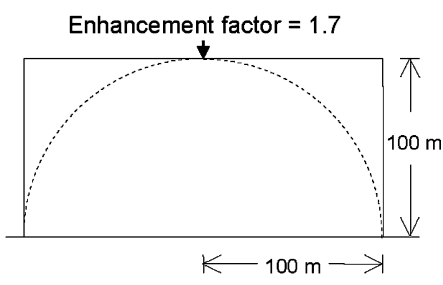

(c)

Fig. 11. (a) Perfectly conducting hemisphere, (b) perfectly conducting discretized hemisphere, and (c) perfectly conducting rectangular parallelepiped, each placed in a uniform electric field. The latter two structures were discretized using $10 \times 10 \times 10 \mathrm{~m}^{3}$ cubic cells for FDTD calculation to obtain the electric field enhancement factor at the highest point of the structure. The hemisphere in (a) is also shown, as a reference, by the broken line in (b) and (c). The electric field enhancement factor for the hemisphere is known from theory and is equal to 3 [32]. Note that the enhancement factor decreases with increasing the size of the flat horizontal area surrounding the field point.

conducting plane that was located $500 \mathrm{~m}$ below another $2000 \times$ $2000 \mathrm{~m}^{2}$ perfectly conducting plane. Four side planes representing Liao's second-order absorbing boundaries [21] were used to avoid reflections there during the transient process before the uniform static electric field is established. A step-function vertical electric field (instantaneously rising to a constant value) is applied between the two parallel planes near their edges. The FDTD-calculated enhancement factor for vertical electric field $E_{z}$ at the top of the staircase-approximated hemisphere, which is evaluated at $200 \mu$ s when the field is essentially static, is 2.5 . This is reasonably close to the theoretical value, 3 (e.g., [32]). The FDTD-calculated enhancement factor for vertical electric field $E_{z}$ at the top of the rectangular parallelepiped, shown in Fig. 11(c), is 1.7. Note that the enhancement factor decreases with increasing the size of the flat horizontal area surrounding the field point.

Table IX gives values of static electric-field enhancement factor due to the presence of perfectly conducting building of plan area $S_{b}=40 \times 40 \mathrm{~m}^{2}$ and height $h_{b}=20,50$, and $100 \mathrm{~m}$ placed in a vertical electric field between parallel $2000 \times$ $2000 \mathrm{~m}^{2}$ perfectly conducting planes. Static electric-field 
TABLE VIII

Peak Values of Vertical Electric Field $E_{z}$ and Azimuthal Magnetic Field $H_{\varphi}$ AT the Ground SuRface Due to a Lightning STRIKe to Flat PERFECTLY CONDUCTING GROUND FOR THE CASE OF $v=c$ CALCULATED USING THE FDTD METHOD AND THOTTAPPILLIL ET AL.'s [19] EXACT ANALYTICAL EXPRESSIONS. LIGHTNING SHORT-CIRCUIT CURRENT WAVEFORM, $I_{\mathrm{sc}}$, HAVING A PEAK OF $11 \mathrm{kA}$ WAS USED

\begin{tabular}{|c|c|c|c|c|c|}
\hline \multirow{2}{*}{ Quantity } & \multirow{2}{*}{ Method } & \multicolumn{4}{|c|}{$d, \mathrm{~m}$} \\
\hline & & 50 & 100 & 200 & 500 \\
\hline$E_{z}$ & FDTD & 13 & 6.7 & 3.3 & 1.4 \\
\hline $\mathrm{kV} / \mathrm{m}$ & Eq. (Al) & 13 & 6.6 & 3.3 & 1.3 \\
\hline \multicolumn{2}{|c|}{ Difference, \% } & 2 & 1 & 1 & 3 \\
\hline$H_{\varphi}$ & FDTD & 36 & 18 & 8.8 & 3.6 \\
\hline $\mathrm{A} / \mathrm{m}$ & Eq. (A2) & 35 & 17 & 8.7 & 3.5 \\
\hline \multicolumn{2}{|c|}{ Difference, \% } & 2 & 1 & 1 & 2 \\
\hline
\end{tabular}

TABLE IX

FDTD-Calculated VAlues of STATIC ElECtRIC-FiELd ENHANCEMENT FACTOR DUE TO THE PRESENCE OF A BUILDING OF HEIGHT $h_{b}=20,50$, OR $100 \mathrm{~m}$ IN A UNIFORM VerTiCAL EleCtRic FiELD. Also GiVEN ARE CORRESPONDING TRANSIENT ENHANCEMENT FACTORS FOR THE CASE OF LightNing Strike to Flat Ground at Distance $d=100 \mathrm{~m}$ FROM THE BUILDING (SEE TABLE I)

\begin{tabular}{l|ccc}
\hline $\begin{array}{l}\text { Type of } \\
\text { enhancement } \\
\text { factor }\end{array}$ & \multicolumn{3}{|c}{ Building height, $h_{b}, \mathrm{~m}$} \\
\cline { 2 - 4 } & 20 & 50 & 100 \\
\hline Static & 1.6 & 2.2 & 3.3 \\
\hline Transient & 1.5 & 2.1 & 2.7 \\
\hline
\end{tabular}

enhancement factors for buildings of height $h_{b}=20,50$, and $100 \mathrm{~m}$ (1.6, 2.2, and 3.3, respectively) are close to corresponding transient electric-field enhancement factors given in Tables I-IV.

\section{REFERENCES}

[1] J. S. Chang, T. G. Beuthe, L. Seto, A. Duft, H. Hayashi, W. A. Chisholm, and W. Janischewskyj, "An investigation of the possible relationships between thundercloud electric fields and the lightning parameters for tall structures," J. Geophys. Res., vol. 96, pp. 13197-13205, 1989.

[2] M. Rubinstein, E. Montandon, and M. Ianoz, "Analysis of multi-station cloud lightning electric field pulses recorded with the Swiss LPATS network," paper presented at the 22nd Int. Conf. Lightning Prot., Budapest, Hungary, 1994.

[3] H. Motoyama, J. Janischewskyj, A. M. Hussein, R. Rusan, W. A. Chisholm, and J. S. Chang, "Electromagnetic field radiation model for lightning strokes to tall structures," IEEE Trans. Power Del., vol. 11, no. 3, pp. 1624-1632, Jul. 1996.

[4] B. Kordi, R. Moini, W. Janischewskyj, A. M. Hussein, V. O. Shostak, and V. A. Rakov, "Application of the antenna theory model to a tall tower struck by lightning," J. Geophys. Res., vol. 108, no. D17, doi:10.1029/2003JD003398, 2003.

[5] J. L. Bermudez, F. Rachidi, M. Rubinstein, W. Janischewskyj, V. O. Shostak, D. Pavanello, J. S. Chang, A. M. Hussein, C. A. Nucci, and M. Paolone, "Far-field-current relationship based on the TL model for lightning return strokes to elevated strike objects," IEEE Trans. Electromagn. Compat., vol. 47, no. 1, pp. 146-159, Feb. 2005.

[6] S. Bonyadi-ram, R. Moini, S. H. H. Sadeghi, and A. Mahanfar, "The effects of tall buildings on the measurement of electromagnetic fields due to lightning return strokes," paper presented at the 2001 IEEE Int. Symp. Electromagn. Compat., Montreal, Canada, 2001.

[7] E. K. Miller, A. J. Poggio, and G. J. Burke, "An integro-differential equation technique for the time domain analysis of thin wire structure, I. The numerical method," J. Comput. Phys., vol. 12, pp. 24-28, 1973.
[8] G. Diendorfer and W. Schulz, "Lightning incidence to elevated objects on mountains," in Proc. 24th Int. Conf. Lightning Prot., Birmingham, U.K., 1998, pp. 173-175.

[9] F. Rachidi, W. Janischewskyj, A. M. Hussein, C. A. Nucci, S. Guerrieri, B. Kordi, and J.-C. Chang, "Current and electromagnetic field associated with lightning-return strokes to tall towers," IEEE Trans. Electromagn. Compat., vol. 43, no. 3, pp. 356-367, Aug. 2001.

[10] D. Pavanello, F. Rachidi, M. Rubinstein, N. Theethayi, and R. Thottappilli, "Electromagnetic environment in the immediate vicinity of a tower struck by lightning," paper presented at the Eur. Electromagn. Symp., Magdeburg, Germany, Jul. 2004.

[11] S. Miyazaki and M. Ishii, "Influence of elevated stricken object on lightning return-stroke current and associated fields," in Proc. 27th Int. Conf. Lightning Prot., Avignon, France, Sep. 2004, pp. 122-127.

[12] Y. Baba and V. A. Rakov, "Lightning electromagnetic environment in the presence of a tall grounded strike object," J. Geophys. Res., vol. 110, D09108, doi:10.1029/2004JD005505, May 2005.

[13] M. D. Johns and K. S. Kreielsheimer, "The form factor of end-on field mills," J. Atmos. Terr. Phys., vol. 29, pp. 489-496, 1967.

[14] R. B. Anderson, "Measuring techniques" in Lightning, vol. 1. R. H. Golde, Ed. New York: Academic, 1977, pp. 437-448.

[15] E. M. Bazelyan, B. N. Gorin, and V. I. Levitov, Physical and Engineering Foundations of Lightning Protection. Leningrad, Russia: Gidrometeoizdat, 1978, p. 223.

[16] D. E. Crawford, "Multiple-station measurements of triggered lightning electric and magnetic fields" M.S. thesis, Univ. Florida, Gainesville, 1998.

[17] K. S. Yee, "Numerical solution of initial boundary value problems involving Maxwell's equations in isotropic media," IEEE Trans. Antennas Propag., vol. 14, no. 3, pp. 302-307, Mar. 1966.

[18] Y. Baba and V. A. Rakov, "On the use of lumped sources in lightning return stroke models," J. Geophys. Res., vol. 110, D03101, doi: 10.1029/2004JD005202, Feb. 2005.

[19] R. Thottappillil, J. Schoene, and M. A. Uman, "Return stroke transmission line model for stroke speed near and equal that of light," Geophys. Res. Lett., vol. 28, no. 18, pp. 3593-3596, 2001.

[20] T. M. Chrisp, G. Starrs, W. J. McCarter, E. Rouchotas, and J. Blewett, "Temperature-conductivity relationships for concrete: An activation energy approach," J. Mater. Sci. Lett., vol. 20, no. 12, pp. 1085-1087, Jun. 2001.

[21] Z. P. Liao, H. L. Wong, B.-P. Yang, and Y.-F. Yuan, "A transmitting boundary for transient wave analysis," Sci. Sin., vol. A27, no. 10, pp. 1063-1076, 1984.

[22] Y. Baba and V. A. Rakov, "On the transmission line model for lightning return stroke representation," Geophys. Res. Lett., vol. 30, no. 24, p. 2294, doi: 10.1029/2003GL018407, Dec. 2003.

[23] Y. Baba and V. A. Rakov, "Voltages induced on an overhead wire by lightning strikes to a nearby tall grounded object," IEEE Trans. Electromagn. Compat., vol. 48, no. 1, pp. 212-224, Feb. 2006.

[24] Y. Baba and V. A. Rakov, "Electromagnetic models of the lightning return stroke," J. Geophys. Res., vol. 112, no. D04102, doi:10.1029/2006JD007222, Feb. 2007.

[25] Y. Baba and V. A. Rakov, "Applications of electromagnetic models of the lightning return stroke," IEEE Trans.Power Del., in press.

[26] C. A. Nucci, G. Diendorfer, M. A. Uman, F. Rachidi, M. Ianoz, and C. Mazzetti, "Lightning return stroke current models with specified channel-base current: A review and comparison," J. Geophys. Res., vol. 95, no. D12, pp. 20395-20408, 1990.

[27] V. A. Rakov, "Lightning return stroke speed," J. Lightning Res., vol. 1, pp. 80-89, Jan. 2007.

[28] W. Janischewskyj, V. Shostak, J. Barratt, A. M. Hussein, R. Rusan, and J.-S. Chang, "Collection and use of lightning return stroke parameters taking into account characteristics of the struck object," in Proc. 23rd Int. Conf. Lightning Prot., Florence, Italy, 1996, pp. 16-23.

[29] F. Fuchs, "On the transient behaviour of the telecommunication tower at the mountain Hoher Peissenberg," in Proc. 24th Int. Conf. Lightning Prot., Birminghan, U.K., 1998, vol. 1, pp. 36-41.

[30] V. A. Rakov, M. A. Uman, K. J. Rambo, M. I. Fernandez, R. J. Fisher, G. H. Schnetzer, R. Thottappillil, A. Eybert-Berard, J. P. Berlandis, P. Lalande, A. Bonamy, P. Laroche, and A. Bondiou-Clergerie, "New insights into lightning processes gained from triggered-lightning experiments in Florida and Alabama," J. Geophys. Res., vol. 103, no. D12, pp. 1411714139, 1998.

[31] V. A. Rakov, "Transient response of a tall object to lightning," IEEE Trans. Electromagn. Compat., vol. 43, no. 4, pp. 654-661, Nov. 2001.

[32] J. A. Stratton, Electromagnetic Theory. New York: McGraw-Hill, 1941, p. 205. 


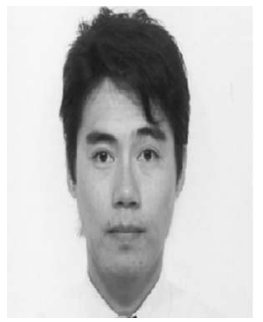

Yoshihiro Baba (S'95-M'99) received the B.S., M.S., and Ph.D. degrees from the University of Tokyo, Tokyo, Japan, in 1994, 1996, and 1999, respectively.

He is currently an Associate Professor in the Department of Electrical Engineering, Doshisha University, Kyoto, Japan. From 2003 to 2004, he was a Visiting Scholar at the University of Florida, Gainesville, on sabbatical leave from Doshisha University. He is the author or coauthor of more than 20 papers published in international journals.

Dr. Baba is a member of the American Geophysical Union, and the Institution of Engineering and Technology, London, U.K.

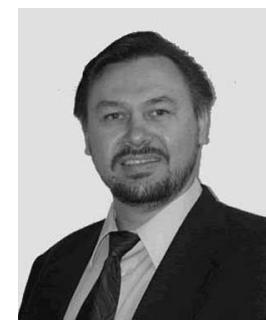

Vladimir A. Rakov (SM'96-F'03) received the M.S. and Ph.D. degrees from Tomsk Polytechnical University (Tomsk Polytechnic), Tomsk, Russia, in 1977 and 1983, respectively.

He is currently a Professor in the Department of Electrical and Computer Engineering, University of Florida, Gainesville, and Co-Director of the International Center for Lightning Research and Testing. From 1977 to 1979, he was an Assistant Professor of Electrical Engineering at Tomsk Polytechnic. In 1978, he joined the High Voltage Research Institute, a division of Tomsk Polytechnic, where, from 1984 to 1994, he was the Director of the Lightning Research Laboratory. He is the author or coauthor of more than 140 papers published in international journals and is a coauthor of a book. He is the holder of over 30 patents.

Dr. Rakov is a Fellow of the American Meteorological Society and the Institution of Engineering and Technology. He is a member of the American Geophysical Union, the Society of Automotive Engineers (now SAE International), and the American Society for Engineering Education. He is serving as the Chairman of the Technical Committee on Lightning of the biennial International Zurich Symposium on Electromagnetic Compatibility. He served as the Chairman of the AGU Committee on Atmospheric and Space Electricity. 